\title{
Experimental Investigations Regarding the Behaviour of Composite Panels Based on Polyurea and Kevlar or Dyneema Layers Under Blast and Fragments
}

\author{
BOGDAN IFTIMIE, MARIN LUPOAE*, OCTAVIAN ORBAN \\ Military Technical Academy Ferdinand I, 39-49 George Cosbuc Av., 050141, Bucharest, Romania
}

\begin{abstract}
This paper presents an experimental study to determine the behaviour of composite panels, made of polyurea sprayed on Kevlar or Dyneema supportlayers, under blast and fragments produced by an improvised explosive device (IED). The fragments used for tests were steel bearing balls of 8 and $10 \mathrm{~mm}$ propelled by a plastic explosive charge and bullets cal. $7.62 \mathrm{~mm}$, type Full Metal Jacketed Armor Piercing (FMJ AP) and Hollow Point Boat Tail (HPBT), with impact velocity greater than $500 \mathrm{~m} / \mathrm{s}$. To determine the fragments attenuation, their velocities before and after the impact with the composite panel were measured and compared. In order to assess the blast attenuation, the reflected pressures measured by two face-on sensors, one of which was covered by the composite panel, were compared. Also, to explain the behaviour of composite panels under blast, the shock polars of materials in the panel's composition were plotted. The results have shown that the composite panels have a low rate of attenuation of fragment velocities but a very good ability to attenuate the pressure and impulse associated with the shock wave.
\end{abstract}

Keywords: soft targets, composite panel, blast, fragments, attenuation

The increasing number of recent terrorist attacks, particularly on soft targets (unprotected objectives) and in public places, requires a continuous concern from national safety authorities. Among the unprotected objectives, the most common targets are the civil airports. Their protection against attacks with improvised explosive devices (IED) is imperative when considering their very large spaces, very large number of passengers and airport staff. In case of an attack, the blast and fragments can be spread at large distances. If a ballistic multi-layered panel is placed between different crow ded areas, then it would be possible to partition these spaces and stop/mitigate the spread of the shock waves and fragments. This ballistic panel has been designed to consist of two symmetrical layers of porous material in order to particularly mitigate the fragments and a central composite panel capable of attenuating in particular the shock wave. The central composite panel, which is the subject of the present paper, was made byspraying the polyurea onto Kevlar or Dyneema support layers, according to the process outlined in [1].

By combining the advantages of an hyperelastic behaviour with an easily application as an additional layer on fabrics or metallic plates, the use of polyurea for composite panels is in line with the current trend tow ards finding modern solutions to reduce the effects associated with impact or explosion [1-7].

Thus, the results obtained from some experimental tests on ballistic protection plates made of Kevlar ${ }^{\circledR}$ and ceramic layers covered with different thicknesses of pulverized layers of polyurea, are presented in [1]. The projectiles used were .44 Magnum Semi J acketed Hollow Point (SJ HP) and have an average impact velocity of $430 \mathrm{~m} / \mathrm{s}$. The results have shown that this configuration of the protection plates offered a III A protection level according to NIJ standard [8]. In the case of IED, the fragments can be of different shapes (nuts, bolts, steel balls, nails, etc.) and their speed exceeds $430 \mathrm{~m} / \mathrm{s}$, which requires additional research to determine the behaviour of the composite panels at higher speeds.
Most of the tests performed on materials and structures designed for ballistic protection aim either to determine the ballistic limit [9-12] or energy absorbed in the penetration process [13]. Due to the constraints imposed on the thickness of the composite panel (maximum $3 \mathrm{~cm}$ ) and the high velocity of the fragments resulting from the detonation of an IED, in the present case there is no question of determining the ballistic limit of the composite panel, but only its ability to attenuate the fragments velocity.

Devices used to propel the impactors to determine the ballistic limit or absorbed energy were represented by the gas gun [11] and the high-speed gas gun [10], resulting in a velocity of up to $450 \mathrm{~m} / \mathrm{s}$. Also, Borvik et al. [9] used different rifles to fire the projectiles with initial velocity of up to $920 \mathrm{~m} / \mathrm{s}$, while Harris et al. [7] have used shock tubes to test the polyurethane mitigation capacity. Regarding the shock wave attenuation by the composite panel, the focus falls on the polyurea layers. Research has shown that a 4 $\mathrm{mm}$ thick polyurea pad can reduce the normalized peak pressure and impulse by about $74 \%$ and $49 \%$, respectively [7].

Under these conditions, the present paper aims to make an assessment of the behaviour of polyurea composite panels under fragments impact in terms of: the type of support layers (Kevlar or Dyneema), the type of the projectile (deformable or non-deformable) and the velocity impact (over $500 \mathrm{~m} / \mathrm{s}$ ). At the same time, an evaluation of the capacity of composite panels to attenuate the blast waves was also carried out.

\section{Experimental part \\ Materials used for panels}

Two types of composite panels were used for tests. They were made by spraying polyurea (Europol ${ }^{\circledR}$ ) on Kevlar or Dyneema support layers. The polyurea was sprayed through a pressurized container at approximately $150 \mathrm{bar}$ and $70-90^{\circ} \mathrm{C}$. The Kevlar Prepreg (composite based on Kevlar fibre and a phenolic resin) and Dyneema type HB24 (Ultra-High Molecular Weight Polyethylene based 
composite laminate) have been used as support layers. The Composite Panel based on Kevlar - CPK consisted of 10 layers of Kevlar and 10 polyurea layers. Also, Composite Panel based on Dyneema - CPD, consisted of 5 layers of Dyneema and 6 layers of polyurea. The densities of composite panels were approximately $870 \mathrm{~kg} / \mathrm{m}^{3}$ for CPK and $910 \mathrm{~kg} / \mathrm{m}^{3}$ for CPD and all composite panels have the dimensions of $500 \mathrm{~mm} \times 500 \mathrm{~mm} \times 2.4 \mathrm{~mm}$ (Fig. 1).
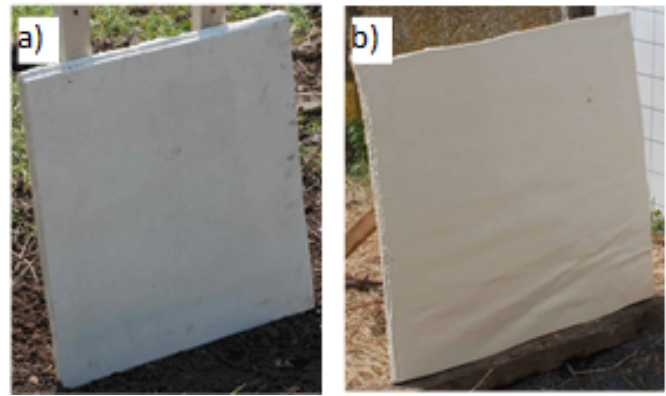

Fig. 1. Composite panels: a) CPK and b) CPD

Types of fragments and projectiles

In order to determine the types of fragments and projectiles, there were considered: i) the types of impactors used in literature [7-9] ( sphere, flat, hemispherical, conical and ogival heads), and ii) the existing cases of IED attacks. Preformed fragments of IED used in the terrorist attacks in London, Madrid, Saint Petersburg were steel bearing balls or nuts whose size did not exceed $\$ 10 \mathrm{~mm}$ or M20. Also, in the tests there were used $7.62 \mathrm{~mm} \times 51 \mathrm{~mm}$ bullets according to standard NIJ 0101.06 [8], whose characteristics are presented in table 1.For the tests performed on the CPK and CPD panels, two types of fragments and projectiles were selected: a) deformable (HPBT bullets) and $b$ ) non-deformable (steel bearing balls and FMJ bullets). Of the possible fragments to be used, steel balls were preferred due to their spherical shape and their homogeneity as compared to any other type of fragments. The diameter of the steel balls used for the tests was $8 \mathrm{~mm}$ and $10 \mathrm{~mm}$.

The initial velocity of the steel balls was estimated using the Gurney equation for an asymmetric sandwich configuration [14]:

$$
\frac{V_{p}}{\sqrt{2 E_{G}}}=\left[\frac{(1+2 \cdot \mu)^{3}+1}{6(1+\mu)}+\mu\right]^{-1 / 2}
$$

where: $V_{p}$ is the initial velocity of the steel balls, in $\mathrm{m} / \mathrm{s}$; $\sqrt{2 E_{G}}$ is the Gurney's constant for the explosive used, in $\mathrm{m} / \mathrm{s} ; \mu=\mathrm{M} / \mathrm{M}_{\text {e }}$ is the ratio of the metallic mass, $M$ (mass of the steel balls) and $M$ is the mass of explosive charge. The steel balls placed in contact with the plastic explosive do not form a continuous mass as in the case of a metal plate. With consideration in this regard, the calculated speed of the steel balls was multiplied by a coefficient which takes into account the ratio of the cross-sectional area of the balls and the cross-sectional area of the explosive charge. Also, the ratio $\mu$ was modified based on the actual mass involved in the propulsion of the balls [15]. The estimated values of the steel balls according to equation (1) are shown in table 2.

\section{Test setup description}

Test setup for steel bearing balls impact

In order to determine the composite panels' attenuation capacity of the metal balls, a test configuration was used to measure the speed before and after passing through the panel. This configuration consisted of the CPK panel, the explosive to propel balls device and the high speed camera (Fig. 2).
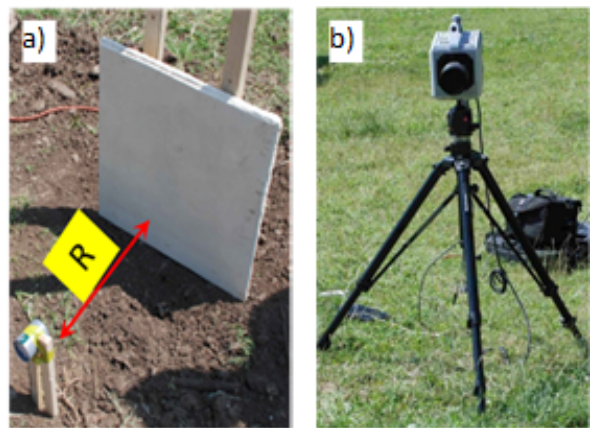

Fig. 2. Test configuration for CPK attenuation under bearing balls impact: a) explosive device and CPK; b) high-speed camera

The explosive balls propulsion devices were preferred to gas gun because it allows a higher velocity of the balls. This device consisted of a PVC tube with outer diameter of $50 \mathrm{~mm}$, plastic explosive charge of Hitex (detonation velocity of $7000 \mathrm{~m} / \mathrm{s}$ at density of $1.5 \mathrm{~g} / \mathrm{m}^{3}$ ) and steel bearing balls. The ratio i between the masses of the balls and the explosive charge was 0.869 for the $8 \mathrm{~mm}$ diameter and 1.087 for the $10 \mathrm{~mm}$ diameter, respectively. Standoff distance $R$ was $3.70 \mathrm{~m}$ for both 8 and $10 \mathrm{~mm}$ ball configurations. For measuring the velocity of the steel balls before and after the perforation of the composite panel, a FASTCAM SA-X2 type 1080-C3 high-speed camera was used, as is presented in figure $2 b$.

\section{Test setup for ammunition cal. $7.62 \mathrm{~mm}$}

For testing the attenuation capacity of composite panels under $7.62 \mathrm{~mm}$ ammunition there were used: rifle, ammunition (according to table 1), CPK and CPD, highspeed camera and ballistic radar for measuring bullet velocity as recommended in NI] 0101.06 [8], as is shown in figure 3.

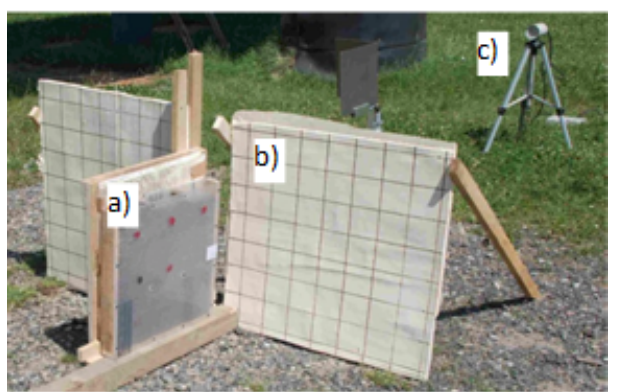

Fig. 3. Testing configuration for composite panels attenuation under bullet impact: a) composite panel; b) grid for high speed camera; c) Doppler radar

\section{Test setup for blast attenuation}

To determine the shock wave attenuation capacity of CPK and CPD composite panels, a test facility consisting of: a) explosive charge support, b) explosive charge of 20 $\mathrm{g}$ plastic explosive; c) wooden plate with $1 \mathrm{~m} \times 1 \mathrm{~m} \times 0.01$ $\mathrm{m}$ dimensions and with a central opening of $0.4 \mathrm{~m} \times 0.4 \mathrm{~m}$

\begin{tabular}{|c|c|c|c|}
\hline $\begin{array}{c}\text { Characteristics } \\
\text { Bullet type }\end{array}$ & Bullet mass [g] & $\begin{array}{c}\text { Initial velocity } \\
{[\mathrm{m} / \mathrm{s}]}\end{array}$ & $\begin{array}{c}\text { Maximum } \\
\text { energy [J] }\end{array}$ \\
\hline Cal. 7.62 mm HPBT & 11.34 & 785 & 3494 \\
\hline Cal. 7.62 mm FMJ AP & 10.70 & 860 & 3957 \\
\hline
\end{tabular}

Table 1

AMMUNITION CHARACTERISTICS USED FOR TESTS 
(Fig. 4). The overpressure was measured by sensors S1 and S3 (PCB 113B26) for face-on pressure and by sensor S2 (PCB 113B27) for side-on pressure. The sensors were disposed at the same distance from the explosive charge, respectively $50 \mathrm{~cm}$. The mass of explosive and the standoff distance to the sensors were chosen to provide a level of the reflected overpressure by approximately $1 \mathrm{MPa}$, comparable to that obtained in [7]. The sensors were connected to a Genesis type GEN7I-2 high speed data acquisition system with a sampling rate of $2 \mathrm{MS} / \mathrm{s}$. The attenuation rate was determined by comparing the reflected pressure recorded by the sensor $\$ 3$, and the reflected pressure recorded by sensor S1, after passing the shock wave through the composite panels.

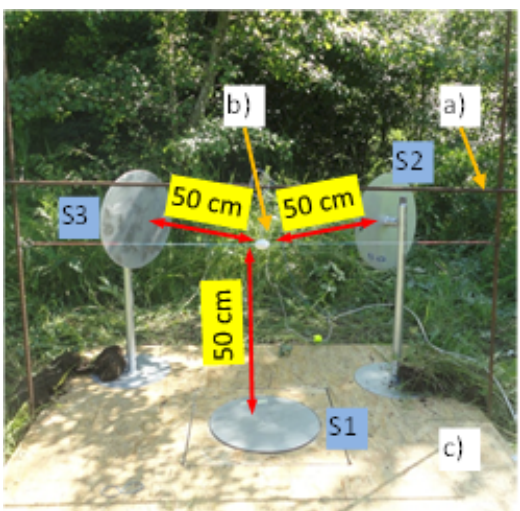

Fig. 4. Testing configuration for composite panels blast attenuation: a) charge support; b) explosive charge; c) wooden plate; $\mathrm{S} 1, \mathrm{~S} 2$ and S3 pressure sensor

\section{Results and discussions}

Bearing balls attenuation

Only composite panels with Kevlar support were used for this test. These panels were perforated by the 8 and 10 $\mathrm{mm}$ diameter balls. Figure 5 shows that in all cases the balls are attenuated by the Kevlar support layer and the main mechanism is delamination, as described by Alil et al. [16] and Balaganesan et al. in [10]. This attenuation mechanism consists of melting, bulging and streaming of fibres, the last feature of which can be seen in figures $5 b$ and $5 \mathrm{~d}$.
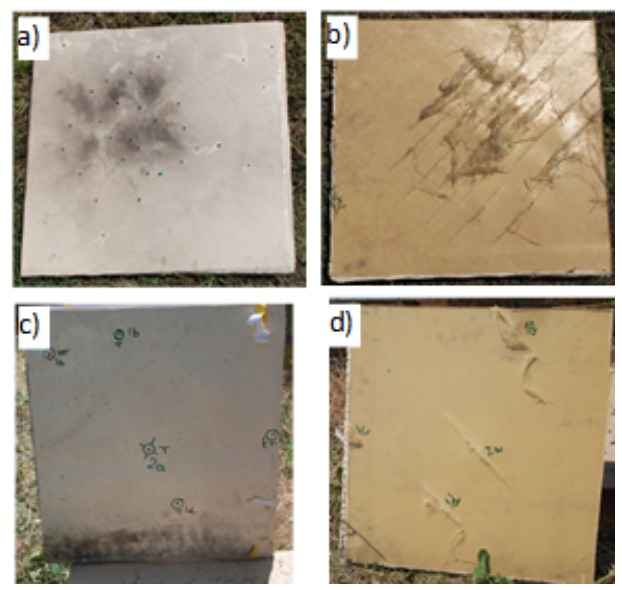

Fig. 5. Impact effects on CPK of $8 \mathrm{~mm}$ ( $5 \mathrm{a}$ and $5 \mathrm{~b}$ ) and $10 \mathrm{~mm}$ ( $5 \mathrm{c}$ and $5 \mathrm{~d}$ ) bearing balls. Pictures $\mathrm{a}$ ) and c) represent front face and b) and d) the back face
The attenuation capacity of the CPK is shown in table 2 . The attenuation of $8 \mathrm{~mm}$ balls is less than the $10 \mathrm{~mm}$ balls attenuation due to the impact velocity on the one hand and the contact surface on the other. Thus, if the attenuation produced on the $10 \mathrm{~mm}$ balls is multiplied by the ratio of the $8 \mathrm{~mm}$ cross-sectional area and that of the $10 \mathrm{~mm}$ balls, an attenuation of $28.23 \%$ is obtained which is approximately equal to that for the $8 \mathrm{~mm}$ balls. This shows that penetration depends both on the impact velocity of the fragment and on the impact surface.

\section{Bullet attenuation}

The experimental tests to determine composite panels attenuation of explosive propelled bearing balls have the advantage of being close to real situations, but have the disadvantage that they are no reproducible. For this reason, NIJ 0101.06 recommendations [8] have been used to test fragments attenuation. Thus, the ability of Kevlar or Dyneema composite panels to attenuate FMJ and HPBT bullets (their characteristics are presented in table 1) was tested. Due to the higher speed and internal structure, the FMJ bullet attenuation by the panels CPK and CPD was less than $3 \%$.

For HPBT deformable bullets, the results obtained are shown in figure 6. Attenuation of bullet velocity was $7.79 \%$ for Kevlar composite panels and $7.13 \%$ for composite panels with Dyneema. This results indicate that the inclusion of Kevlar and Dyneema layers and their dispersion among the polyurea layers does not allow the mitigation of fragment velocity by elastic deformation mechanism (free movement of the layers of Kevlar and Dyneema is prevented due to the polyurea layers).

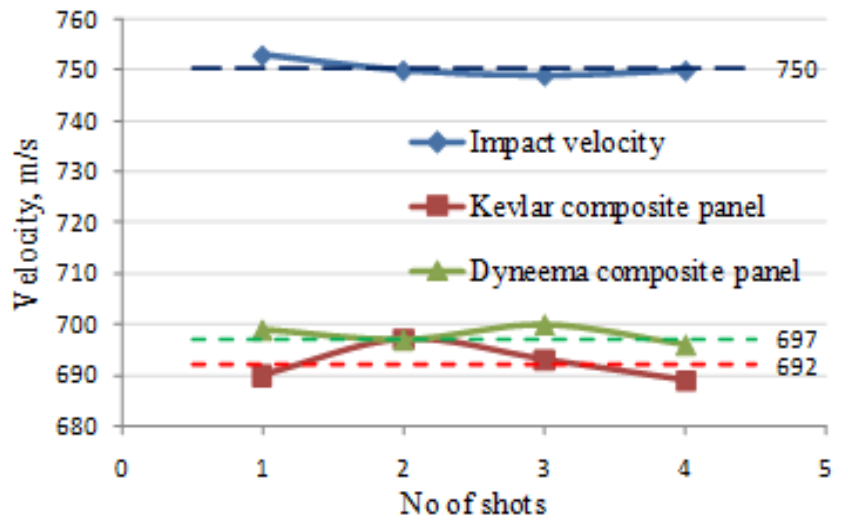

Fig. 6. Attenuation of CPK and CPD under HPBT bullet impact

These results are in line with those reported in the literature for the attenuation of projectiles with speeds of around $270 \mathrm{~m} / \mathrm{s}$ by 8 layers of Kevlar [17]. In addition, the capacity of ballistic composite panels made of porous steel slag layers and CPK or CPD to mitigate HPBT bullets was tested. The results show that two exterior 2 layers of $3 \mathrm{~cm}$ thickness of steel slag and a CPK or CPD as central panel have a $82 \%$ attenuation capacity for HPBT bullets. For the complete mitigation of HPBT bullets, the thickness of the steel slag layer must be at least $4 \mathrm{~cm}$.

\begin{tabular}{|l|c|c|c|c|}
\hline \multirow{2}{*}{$\begin{array}{c}\text { Characteristic } \\
\text { Diameter of the ball }\end{array}$} & $\begin{array}{c}\left.\text { Theoretical velocity }{ }^{1}\right) \\
{[\mathrm{m} / \mathrm{s}]}\end{array}$ & \multicolumn{2}{|c|}{$\begin{array}{c}\text { Experimental velocity } \\
{[\mathrm{m} / \mathrm{s}]}\end{array}$} & \multirow{2}{*}{ Atenuation, \% } \\
\cline { 3 - 4 } & & impact & final & \\
\hline$\Phi 8 \mathrm{~mm}$ & 710 & 726 & 529 & 27.13 \\
\hline$\Phi 10 \mathrm{~mm}$ & 571 & 526 & 294 & 44.11 \\
\hline
\end{tabular}

Table 2

CPK VELOCITY ATTENUATION

$\left.{ }^{1}\right)$ Theoretical velocity determined according to equation (1). 


\section{Blast attenuation}

Mechanisms of blast attenuation

The blast attenuation of CPK and CPD is due in particular to the polyurea mitigation features. The main mechanisms underlying the attenuation of the shock wave by the polyurea are considered as follows [18]: a) Shock-waveinduced hard domain ordering; b) Shock-wave-induced hard domain crystallization/densification; c) Shock wave induced hydrogen bond cleavage and formation; d) Viscoelastic stress relaxation within the hard-domains/soft matrix interfacial regions; e) Shock wave capture and neutralization. Of all these mechanisms, the latter is one that can easily be highlighted. In a layered heterogeneous material system, e.g. multi-layered composite panel made of polyurea and Kevlar or Dyneema, a leading shock front is followed by a release wave which reportedly catches up with and attenuates the leading shockwave thereby leading to shock attenuation [19]. This dual shock-wave pattern is attributed to the material architecture through which shock wave propagates, i.e. the shock characteristics. To illustrate the importance of the shock characteristics on the shock wave attenuation, the shock polars of the materials used to make the composite panels (polyurethane, Kevlar or Dyneema) and also of three different materials such as polystyrene, polyethylene and steel were plotted and compared, figure 7. To plot the shock polars of the materials, the follow equation was used:

$$
p-p_{0}=\rho_{0}\left(c_{0} \cdot u+s \cdot u^{2}\right)
$$

where: $p_{0}$ is the atmospheric reference pressure, $c_{0}$ is bulk sound speed and $s$ is a constant of material. The shock characteristics of these materials are shown in table 3.

Table 3

SHOCK CHARACTERISTICS OF MATERIALS

\begin{tabular}{|l|c|l|c|c|}
\hline Material & $\rho_{0}\left[\mathrm{~g} / \mathrm{cm}^{3}\right]$ & $c_{0}[\mathrm{~km} / \mathrm{s}]$ & $\mathrm{s}$ & Ref. \\
\hline Polyureea 1000 & 1.098 & 2.901 & 2.13 & {$[21]$} \\
\hline Kevlar filled EPDM & 0.923 & 1.660 & 2.03 & {$[22]$} \\
\hline Dyneema & 0.950 & 1.770 & 3.45 & {$[20]$} \\
\hline Iron & 7.850 & 4.722 & 1.44 & {$[15]$} \\
\hline Polyethylene & 0.915 & 2.901 & 1.48 & {$[15]$} \\
\hline Polystyrene & 1.044 & 2.746 & 1.32 & {$[15]$} \\
\hline
\end{tabular}

The characteristics of the induced shock (shock wave velocity, material velocity and pressure) produced by the contact detonation of an explosive charge in different materials can be determined by intersecting the shock polars of the materials with the isentropic of detonation products (Fig. 7). It can be seen that the arrival of a shockwave to an interface of polyurea, Kevlar or Dyneema material is associated with a slow rate of pressure transfer. Unlike these materials, in case of the steel the induced pressure is even higher than the Chapman - Jouguet (CJ) state values.

\section{Attenuation of the shock wave by CPK and CPD}

To determine the rate of attenuation produced by the CPK and CPD panels, the value of the reflected pressure recorded by the sensor S1 (this sensor was covered with a CPK or CPD panel) was compared with the reflected pressure measured by the S3 sensor. Firstly, there were recorded some reference values of overpressure. The recorded values of sensor S1 (face-on), sensor S2 (sideon) and sensor S3 (face-on) without application of any sample above sensor S1 are shown in figure 8. The measured values are the overpressures and zero value in the graphs of figure 8 corresponds to atmospheric pressure. The maximum overpressure values recorded by sensors

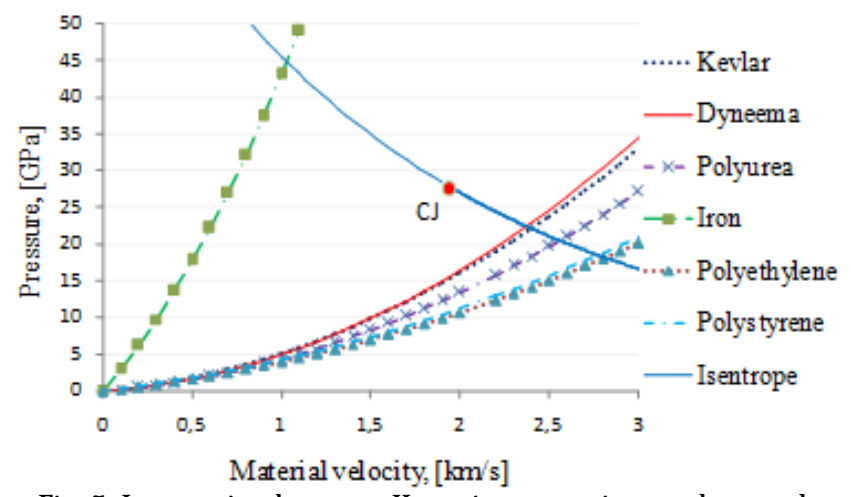

Fig. 7. Intersection between Hugoniot curves in p-u plane and isentrope of detonation products

S1 and S3 are similar, approximately $0.87 \mathrm{MPa}$, while the impulse associated with the overpressure variation curve for sensor S1 is $0.081 \mathrm{MPa} \cdot \mathrm{ms}$ and $0.102 \mathrm{MPa} \cdot \mathrm{ms}$ for sensor S3, respectively.

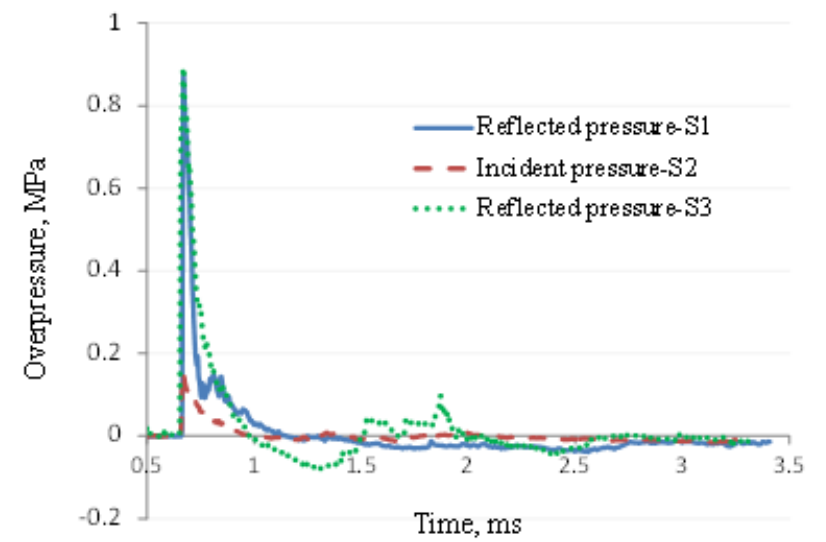

Fig. 8. Reference values of overpressures

After adding the CPK or CPD composite panel over the S1 sensor, it is observed an attenuation of the reflected pressure recorded by this sensor comparing with the value measured by sensor S3 (Fig. 9).

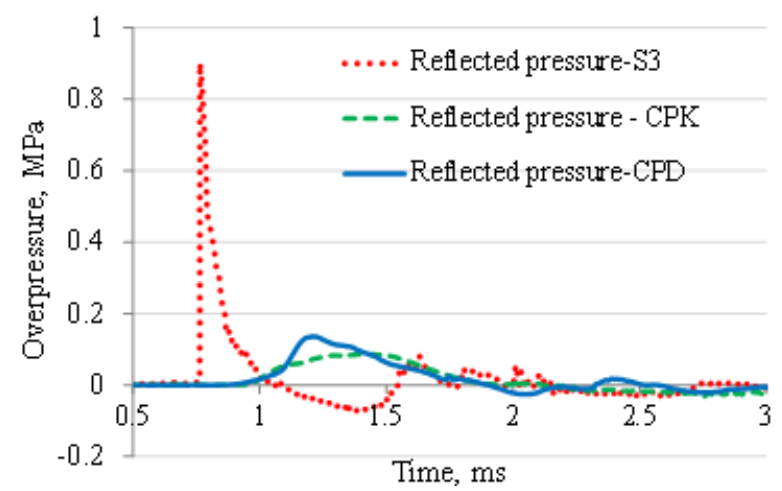

Fig. 9. Shock wave attenuation by CPK or CPD panels

The maximum reflected overpressure value recorded by the S1 sensor when the shock wave passes through the CPK or CPD composite panels is $0.12 \mathrm{MPa}$ for CPD and $0.09 \mathrm{MPa}$ for CPK, indicating a 90\% pressure attenuation for CPK and $87 \%$ for CPD. It can also be noticed that in both cases of using composite panels, a shock wave delay occurs (there is an increase of the time of arrival at sensor S1). This delay is approximately equal to the duration of the positive phase for the pressure measured by $S 3$, namely $0.259 \mathrm{~ms}$. It should be noted that the positive phase duration for the reflected pressures measured by $S 1$, after the shock wave passed through CPK or CPD panels (approximately $0.898 \mathrm{~ms}$ for each case), is greater than the positive phase duration of pressures recorded by the S3 sensor. By 
measuring the areas under the pressure-time curves, the impulses of positive phases were determined. By comparing these areas with the area under the pressuretime curve recorded by the S3 sensor, an impulse attenuation of $16.29 \%$ for CPK and $6.17 \%$ for CPD, respectively was determined.

\section{Conclusions}

The use of multi-layered ballistic panels to mitigate the effects of improvised explosive devices in large openings (airports) is in line with the current trend to increase the protection of soft targets. The advantages of such panels are mobility and high capacity to reduce the effects of shock waves and fragments. The panels were designed to consist of two layers of porous materials arranged externally, with the main purpose of attenuating the fragments, and a central composite panel with a primary role in the attenuation of the shock wave. The purpose of this paper was to present the results obtained from experimental tests performed on $24 \mathrm{~mm}$ thick composite panels obtained by spraying polyurea on Kevlar (CPK) or Dyneema (CPD) support layers. Tests were performed to determine the CPK and CPD attenuation of deformable (7.62 mm HPBT type ammunition) and non-deformable (steel balls of 8 and $10 \mathrm{~mm}$ diameter and $7.62 \mathrm{~mm} \mathrm{FM}$ ) type ammunition). The results obtained show that the CPK and CPD panels have a mitigation capacity of less than 3\% for FMJ type ammunition. In the case of HPBT ammunition, the attenuation is $7.13 \%$ for CPK and $7.79 \%$ for CPD panels. The attenuation rate of the non-deformable steel balls is higher than for $7.62 \mathrm{~mm}$ bullets, the attenuation percentage being $27.13 \%$ for $8 \mathrm{~mm}$ diameter balls and $44.11 \%$ for balls of $10 \mathrm{~mm}$ diameter. These data show that the speed and impact area, as well as the inner structure of the projectile, are important characteristics to be taken into account in determining the attenuation percentage. However, CPK and CPD panels are not suitable for use as protection systems under deformable or non-deformable projectile. The small number of layers of Kevlar and Dyneema used in the composite panel, as well as the fact that these layers have been dispersed in the composite and have not been able to move freely, are among the probable causes of the very low ability to attenuate the projectiles. Concerning the shock wave attenuation, the experimental tests have shown that the CPK composite panels had a percentage of attenuation of the reflected pressure and impulse by approximately $87 \%$ and $16.29 \%$, respectively. In the case of the CPD panel, the pressure attenuation was of about $90 \%$ and the impulse mitigation was approximately of $6.2 \%$. The plotting of the shock polars of the materials used to make the composite panel (Kevlar, Dyneema and polyurea) showed that the internal structure of the material, quantified by its shock characteristics, plays an important role in the way of the pressure in front of the shock wave is reflected on the interface or is transmitted in the material. For the polyurea, this transmitting capacity is lower than for Kevlar and Dyneema, and this shows that it is responsible for the high shock wave attenuation capacity of the composite panels.

Acknowledgements: The work was partially supported by the grant FSI - EU grant ROFSIP20160S6A12P01.

\section{References}

1.PETRE, R., ZECHERU, T., PETREA, P., GINGHINA, R., SANDU, S., MURESAN, M., MATACHE, L.C., SAVA, A.C., NEATU, F., Mat. Plast., 55, no. 3, 2018, p. 315-319

2.FEAGA, M., The effect of projectile strike velocity on the performance of polyurea coated RHA plates under ballistic impact - Dissertation, Lehigh University, 2007

3.XUE, L., MOCK, Jr.W., BELYTSCHKO, T., Mechanics of Materials, 42 , no 11,2010, p. 981-1003

4.SHIM, J., MOHR, D., Mechanics of Materials, 43, no 7, 2011, p. 349360

5.AMINI, M.R., ISAACS, J., NEMAT, S., Mechanics of Materials, 42, no. 6, 2010, p. 628-639

6.ROTARIU, A., BUCUR, F., TOADER, G., LUPOAE, M., SAVA, A.C., SOMOIAG, P., CIRMACl, M., Mat. Plast., 53, no 4, 2016, p. 670

7.HARIS, A., LEE, H.P., TAN, V.B.C., Defence Technology, 14, no 1, 2018, p. $12-18$

8.***NIJ STANDARD 0101.06, Ballistic resistance of body armour, 2008 9.BØRVIK, T., DEY, S., OLOVSSON, L., Int. J. Impact Engineering, 75, no 8,2015, p. 123-139

10.SEVKAT, E., Int. J. Impact Engineering, 45, no 1, 2012, p. 16-27

11.BALAGANESAN, G., VELMURUGAN, R., SRINIVASAN, M., GUPTA, N.K., KANNY, K., Int. J. Impact Engineering, 47, no 3, 2014, p. 57-66

12.ALAVI, A., RAZAVI, S.B., MAJZOOBI, G.H., Materials Science and Engineering $A, 488$, no $1-2,2008$, p. 273-280

13.CHIAN, S.C., TAN, B.C.V., SARMA, A., Int. J. Impact Engineering, 105 , no 4, 2017, p. 80-88

14.ZUKAS, J.A., WALTERS, W., Explosive Effects and Applications, Springer-Verlag, New York, 1998

15.COOPER, P.W., Explosives engineering, Wiley, 1997

16.ALIL, L.C., ARRIGONI, M., DELEANU, L., ISTRATE, M., Mat. Plast., 55, no 3, 2018, p. 364-371

17.ZHU, D., VAIDYA, A., MOBASHER, B., RAJ AN, S.D., Composites: Part B, 56, 2014, p. 254-262

18.IQBAL, N., TRIPATHI, M, PARTHASARATHY, S. KUMARB, D., ROY, P. K., RSC Adv., 11, no 6, 2016, DOI: 10.1039/c6ra23866a

19.GRUJICIC, M., SNIPES, J. S., RAMASWAMI, S., YAVARI, R., RAMASUBRAMANIAN, M. K., J. Mater. Eng. Perform., 23, 2014, p. 49-64 20.HAZELL, P. J., APPLEBY-THOMAS, G. J., TRINQUANT, X., CHAPMAN, D. J., J ournal of Applied Physics, 110, 2011, DOI: 10.1063/1.3622294 21.MOCK, W., BARTYCZAK, S., LEE, G., FEDDERLY, J., JORDAN, K., AIP Conference Proceedings 1195, 2009, DOI: 10.1063/1.3295029 22.PACHECO, A. H., DATTELBAUM, D.M., BRUCE ORLER, E., BARTRAM B.D., GUSTAVSEN, R.L., J. Phys.: Conf. Ser. 500 18, 2015

Manuscript received: 17.05 .2019 